Segarra Ll., Herrera R. F., Alarcón L. F. and Pellicer E. (2017). "Knowledge Management and Information Flow Through Social Networks Analysis in Chilean Architecture Firms.” In: LC3 2017 Volume II Proceedings of the 25th Annual Conference of the International Group for Lean Construction (IGLC), Walsh, K., Sacks, R., Brilakis, I. (eds.), Heraklion, Greece, pp. 413-420. DOI: https://doi.org/10.24928/2017/0244

\title{
KNOWLEDGE MANAGEMENT AND INFORMATION FLOW THROUGH SOCIAL NETWORKS ANALYSIS IN CHILEAN ARCHITECTURE FIRMS
}

\author{
Lluís Segarra ${ }^{1}$, Rodrigo F. Herrera ${ }^{2}$, Luis F. Alarcón ${ }^{3}$ and Eugenio Pellicer ${ }^{4}$
}

\begin{abstract}
In the Architecture, Engineering and Construction (AEC) sector, information flow and knowledge management influence how companies organize, work and produce, which can be represented in a social network analysis (SNA). Information flows are a critical activity for the work done in architecture firms. The objective of this study is to analyse the social structure of architecture firms to determine how to address information flow and knowledge management. The study is part of benchmarking research related to SNA, management practices and Key Performance Indicators (KPI) in architectural offices. After an extensive literature review, a survey was implemented to develop the SNA. Findings show network type shown by the office depends on its organizational infrastructure. There are also behavioural patterns; it is possible to observe that as the firm's size increases, the density of the work-related connections in the network decreases and the average length of the path between the nodes within the network increases. Therefore, we can conclude that when offices have more human resources, as well as a pyramid structure and defined hierarchy, information flow is concentrated in small groups.
\end{abstract}

Keywords: Social network analysis, architecture firms, survey, organizational structure, knowledge management and information flow.

\section{INTRODUCTION}

Currently, in the Architecture, Engineering and Construction (AEC) industry, information flow and knowledge management influence how companies organize, operate and produce. A social network analysis (SNA) can be used as an effective diagnostic tool so as to highlight a hidden flow of another type of important information (Alarcón et al. 2013)

According to Castillo et al. (2016), there is a relationship between key performance indicators (KPIs) and the metrics obtained by SNA in construction projects where the Last Planner System lean tools are applied. Therefore, it would be interesting to corroborate if these correlations are present in architecture firms, since the design phase is where the greatest impact can be made on an overall construction project.

Leadership development professionals are interested in social networks (SNs) as a way to strengthen relationships between leaders in these fields, communities and organizations

1 Master student, Department of Civil Engineering, Universitat Politécnica de Valéncia, Valencia, España, segarra.lluis@gmail.com

2 PhD student, Department of Construction Engineering and Management, Pontificia Universidad Católica de Chile, Professor of School of Civil Engineering, Pontificia Universidad Católica de Valparaíso, Chile, Researcher - GEPUC, Santiago, Chile, rodrigo.herrera@pucv.cl

3 Professor, Ph.D., Department of Construction Engineering and Management, Pontificia Universidad Católica de Chile, Santiago, Chile, lalarcon@ing.puc.cl

4 Professor, Ph.D., Department of Civil Engineering, Universitat Politécnica de Valéncia, Valencia, España, pellicer@upv.es 
(Hoppe and Reinelt 2010), given that the person and their connectivity play a fundamental role in the success or failure of projects, and they should be managed and continuously improved (Flores et al. 2014). Likewise, the forecasted performance of a construction organization helps to identify weak spots, as well as to find solutions to improve performance and increase benefits (Zayed et al. 2012).

The ownership and administration of an architecture firm have been noted as critical organizational variables in the determination of the results of a professional service company. It is known that company size is a relevant factor which influences the organizational structures that are adopted by architecture firms (Oluwatayo and Amole 2014).

Information flow is a critical activity in architecture firms due to the type of work they do; hence, that is why it is necessary to study how the flow of information and knowledge management occurs, since it is often not visible at first glance (Alarcón et al. 2013).

This study is part of benchmarking research for architecture firms which is being done by Pontificia Universidad Católica de Chile (PUC) and Universidad Técnica Federico Santa María (UTFSM) as well as the Asociación de Oficinas de Arquitectura de Chile (AOA), under the umbrella of project CORFO INGENIERÍA 2030.

The overall objective is to create benchmarking among architecture firms, correlating the organizations' management practices, SNAs and KPIs. The goal of this article is to evaluate and analyse the social structure of architecture firms to determine how information is handled and knowledge management occurs in each of these offices, and then to compare them and to detect patterns.

This article is based on quantitative research with a clearly defined structure. It begins with a review of the literature to understand the initial state. Then the methodology used for the data gathering is described. This is then followed by the results and discussion, and finally the conclusions and a few guidelines for action.

\section{BACKGROUND}

\subsection{Architecture Firms}

According to Oluwatayo and Amole (2013), in the case of most architecture firms, the level of information that flows within their structures is moderate - to - high, whereas the level of centralization is generally low. This is due to the fact that the owners are managers; their roles as partners and in actual management roles influence the structure of the office. The results of a study of 92 architecture firms revealed a significant direct relationship between the type and the size of the formal legal structure. Also, even though these companies have specialized knowledge, the study indicated that there is not a significant relationship between the leadership characteristics and the performance of the architecture firms.

Research by Oluwatayo and Amole (2014) confirmed that only one of the internal factors of the study, specifically the size of the firm, influenced a company's organizational structure. They arrived at the conclusion that organizational structures work better when some external influences are high, resulting in an increased benefit; this drove the conclusion that the Directors of the architecture firms should consider external factors when choosing an organizational structure for their offices, objectively determining the external factors that will exert influence on their companies. 


\subsection{Organizational Structures}

Research by Greenwood R and Empson (2003) strived to clarify what types of organizations could be effective in the administration of professional organizational services, concluding that the most effective was when the professional organization was constituted as a private corporation where the principal asset is specialized labour. Given that conclusion, Zhou and Wit (2009) described the overall structure of an organization in terms of specialization, centralization and formalization; the structural organization of a company is the way it is organized and coordinates the work. In addition, according to Oluwatayo and Amole (2013) there are not many descriptions of the structure of architecture firms in these terms, and generally a low level of specialization is observed in them. They also envision a level of decentralization in most of companies.

\subsection{Social Network Analysis}

According to Anklam (2003), the development of an organization to fulfil its objectives and to reach its stated goals is based on relationships between the individuals that make up the company. The SNA is a technique that has been applied as a Lean Tool to study the impact of Lean Management on continuous improvement, and it can be used to analyse and discern behavioural patterns within an organization, which provides value to areas of interest within an organization (Priven and Sacks 2013; Castillo et al. 2015; Castillo et al. 2016). The SNA is also useful to discover the importance of informal structures that coexist with formal structures within the organization. It serves as a way to adapt the structure of the organization, within a short period of time, as well as to organize solid, strong teams with respect to knowledge transfer (information flow). Finally, it can also be used to develop a relationship of close teamwork (Flores et al. 2014).

SNA can be used to detect patterns such as bottlenecks between teams, areas, groups and information sources, as well as identify disconnected areas or teams. We can better understand the organizational networks, observing connections between nodes and their collaborations, as well visualizing the characteristic patterns of networks such as groupings, and people's proximity or distance (Alarcón et al. 2013).

\section{MEthodology}

For this study, we worked with the employees of nine architecture firms belonging to the AOA. Information was gathered regarding SNA, management practices and KPIs for these organizations. To develop the measurement instruments, multiple workshops of collaborative work were held in some of the offices with the researchers from PUC and UTFSM.

\section{1: DEFINE MODEL SETTINGS}

The questions were developed and validated by experts; the questions were adapted to the organizational model being studied. The participants of all the architecture firms responded to a survey to identify each of the networks. Networks were modeled for work interaction, exchange of work information as well as exchange of information regarding new ideas. Three networks were chosen which explained how work information and new ideas flowed within the organizations. 
Knowledge Management and Information Flow Through Social Networks Analysis in Chilean Architecture Firms

\section{2: COLLECTING DATA WITH A SURVEY}

Interviews were done with each office, using a virtual platform. The questions included: (1) Indicate the following individuals with which you have had a work interaction during the past 6 months; (2) of the individuals indicated by you, what is the frequency that you deal with relevant information regarding your work, (3) indicate how often you develop innovative work ideas with these people. The first question is a discriminatory question. The other two are based on a four point Likert scale. The four points are: "Less than once per month", "One to three times per month", "One to four times per week" and "Once or more times per day".

The required sample from each company was calculated to obtain a 95\% confidence level. Questions 2 and 3 were done with a reliability analysis, receiving a Chronbach's Alpha of 0.755 , which indicates that the test is reliable.

\section{3: PROCESS DATA}

Data in Excel was exported to the free Gephi software, version 0.9.1. The choice to use this software, rather than other software, was the weight that experts give to it, as well as the open license agreement and the fact that it was free. Finally, the information was processed with the Force Atlas algorithm, which is designed to capture SN (Bastian et al. 2009)

\section{4: EXAMINE DATA}

The results were examined to determine connections or bottlenecks between teams and areas, organizational groups, as well as disconnected areas or groups and/or those that are too connected and act as a reference for organizational information. Alarcón et al. (2013) also state that it is important to take into account that the results of the analysis do not provide answers, but rather they indicate where and how we should ask questions. To examine data networks, we used network edges, medium degree, network diameter, network density and medium length of the path. And for the nodes was node in-degree, isolated nodes, referential nodes, intermediary nodes and node closeness, in the manner of Flores et al. (2014).

\section{5: DISCOVER THE CONTEXT}

Individual interviews were conducted with each office to understand the context of the data obtained. Through these interviews, we were able to understand the graphs, the network diagrams and the metrics obtained in the analysis.

Through these interviews, we were able to understand the office's type of organizational structure, as well as the level of hierarchy and the model of information flow that exemplifies each office. We also asked them about the number of groups they were divided into and the size of projects they were implementing at the time the network information was gathered. To understand the networks, we asked questions developed by experts: Are there projects in their final phase that require a larger concentration of human resources? Are there communication channels available for isolated groups? Is it necessary to have teams that are isolated by their work capacity? Have new human resources been incorporated lately? Do you know if any human resources want to leave the organization or are going to leave? Should these work areas be connected? 


\section{6: DEFINE AN ACTION PLAN}

Anklam (2003) suggested three types of interventions to change the behavior patterns of organizations, which are: structural/organizational, the development of the knowledge network and individual/leadership. These interventions are used to read the networks and to adapt the organization. They can also be used to visualize patterns that are intuitively known to exist. These interventions also review the positions of the nodes. The idea is to create a structure that can adapt in real time to the organization's demands.

\section{Results AND Discussion}

The interviews resulted in the identification of networks, and their metrics, for nine architectural companies to understand the information flow and knowledge management in architectural firms. The intent of the research was to identify the relationship between the size of the networks and the metrics obtained.

The first network created was the network of overall interactions for a period of six months. This network did not discriminate by the amount or type of information that was transmitted. In fact, the networks of frequent work information and new idea information are sub-networks of the first, since they determine types of interactions with the individuals cited in the first question (Alarcón et al. 2013).

Consistent with the research done by Alarcón et al. (2013) and Flores et al. (2014), the higher density network -connections obtained among possible connections in the networkwas the overall interaction network, reaching $90.5 \%$ for office A and $34.9 \%$ of office I; whereas in the case of the frequent information network, the metrics dropped to $54.8 \%$ for office A and $11.7 \%$ for office I. We were observed that the density diminished as the number of nodes increased. Also, density was directly related to the size of the officesnodes; the larger the office, the less interconnected it was. In other words, the office with the fewest number of nodes had more resources to share relevant information (Flores et al. 2014). We could also observe that when there were more nodes, the median length of the path-average steps necessary to connect all the nodes in the network to each otherwas longer (Figure 1).

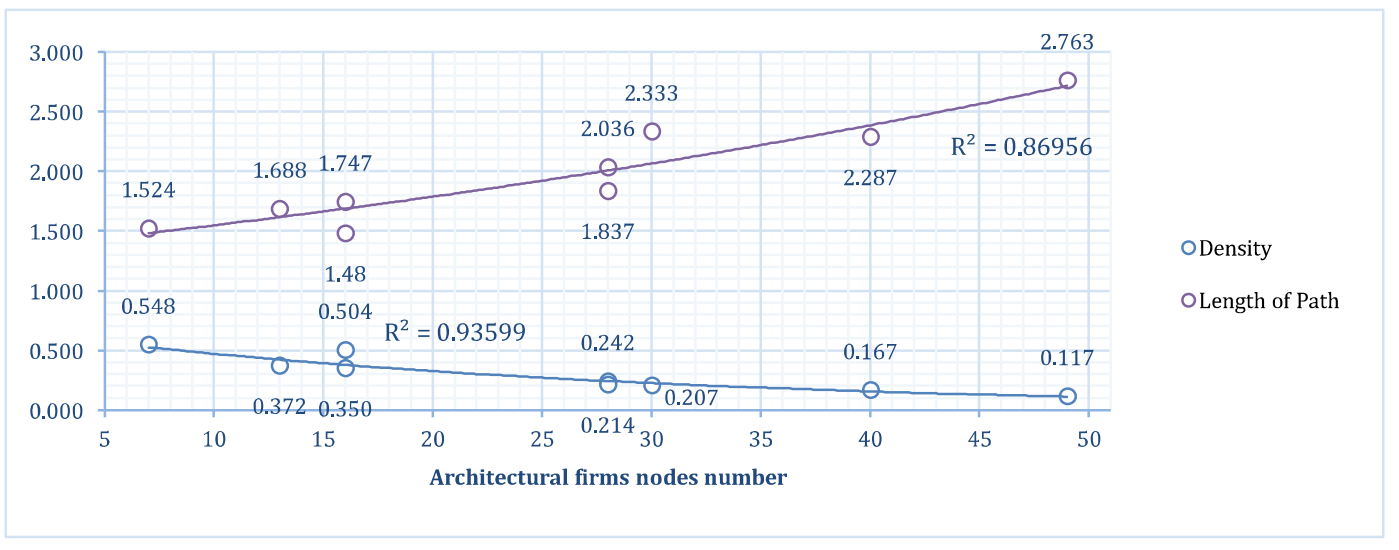

Figure 1: Relationship between the number of nodes, density and the median length of the path.

When we completed step 5 of the methodology -identifying the context of the officeswe found relationships between many variables. The interacting variables included: a) the work structures, b) the disposition of the human resources, c) the productive groups 
separated by size when the data was collected, d) densities, e) median length of path, and f) shape of the networks. We found that there is a direct relationship between the resulting networks and the formal structure that the companies adopted as organizations. There is a clear difference between the two visual forms of the network; Office D network had a circular shape and Office I had a star shape (Figure 2). The one with the circular shape is related to greater integration of the information flow (Flores et al. 2014). Also, the difference in the nodes indicated that when the nodes increased in size, these were named by a greater number of other nodes of the organization, represented by the connectivity lines between them. Office D, which was the smallest, had a basic functional structure that currently is migrating toward a matrix organization. We observed that the floor layout and the office distribution do not have architectural barriers. The form obtained was practically round. On the other hand, Office I has a very hierarchical pyramid structure and is divided into three stories in one building. In this case -and with other two offices-, we observed that the resulting network was in the shape of a star.

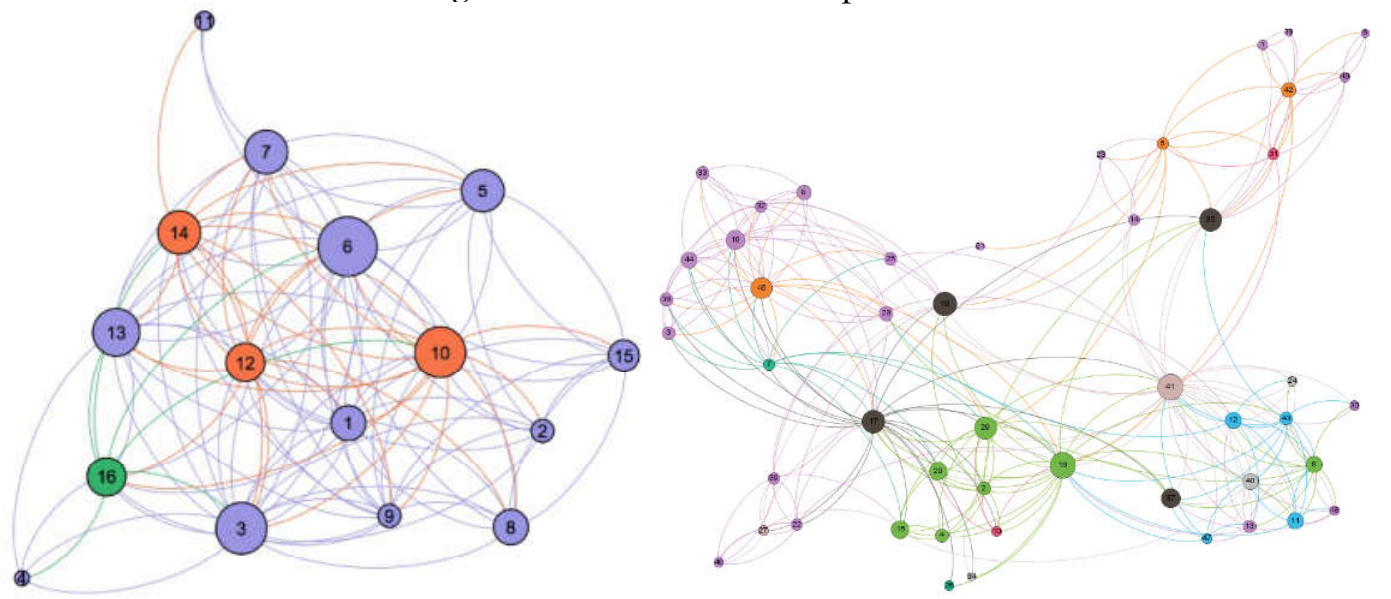

Figure 2: Frequent work information networks from office D and Office I.

Finally, we observed that the density percentage of the frequent work information network is directly related to the number of work groups that the offices indicated that they had at the time the snapshot was taken (Figure 3). For example, the higher density of work information flow network was $54.80 \%$ that corresponded a firm with two teams and the lower density of work information flow network was $11.70 \%$ that corresponded a firm with nine teams.

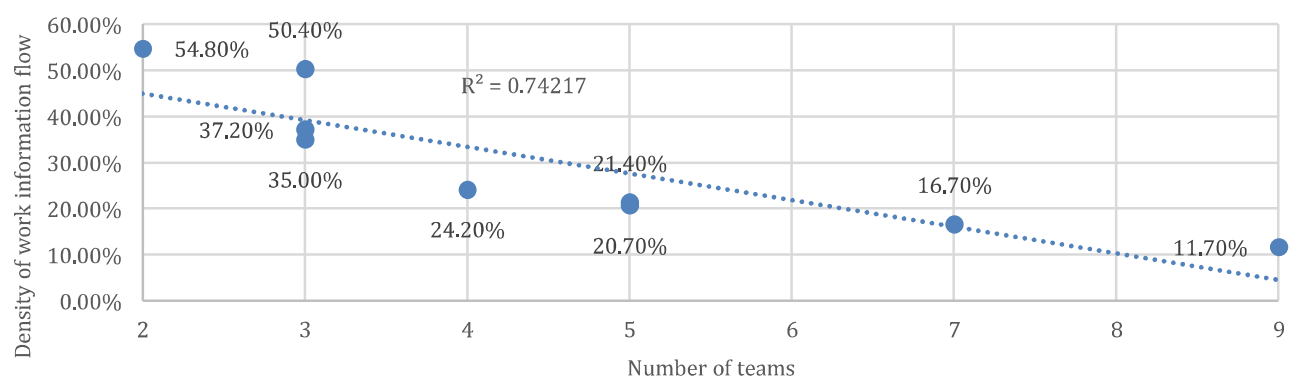

Figure 3: Relationship between the density of the frequent information network and the number of work teams in each office. 


\section{CONCLUSIONS}

The results presented indicate the following conclusions:

Similar to the analysis of AEC industries, the analysis of the architecture firms also generated opportunities for improvement. Offices with a highly hierarchical structure tended to have a network structure in the shape of a star (e.g. Figure 2 Office I), whereas offices with basic functional or matrix structures tended to have a round network structure (e.g. Figure 2 Office D). At the same time, we could see that organizations with basic functional or matrix structures were the smallest firms (few nodes) and the biggest were hierarchically structured companies (many nodes). This allowed us to confirm that when there are fewer nodes, there are more resources to share relevant information; because relationships and communication within small groups is easier. Therefore, information flow and knowledge management were direct because they travelled a shorter distance.

As indicated by Flores et al. (2014), in the first feedback meeting it became clear that it would be difficult to interpret the results, and then later translate them and incorporate them into actions. They recommended the development of a methodology that integrates SNA with relevant concepts of organizational psychology to provide specific suggestions and to envision opportunities for change.

Finally, the research was limited to the initial survey of networks in architecture firms; there were similarities with AEC industries, but it is important to note that it was a snapshot in a moment of the life of the companies. The results obtained represent the temporary limited reality for the research period (Castillo et al. 2015). To add value and to know if there is improvement, it would be necessary to undertake a second study. That would make it possible to see if specific actions resulted in improvements or not. Also, it is important to study the correlation that exists between the SNA metrics, the KPIs and the management practices that are evidenced in the benchmarking study.

\section{ACKNOWLEDGMENTS}

We thank our colleagues in GEPUC and GEPRO. We also thank our universities - UPV and PUC - for considering us for this research. Also, we thank the companies in AOA for providing us with their organizational structures and sharing how they work. Finally, we acknowledge financial support for PhD studies from VRI of PUC.

\section{REFERENCES}

Alarcón, D. M., Alarcón, I. M. and Alarcón, L. F. (2013). Social network analysis: A diagnostic tool for information flow in the AEC industry. In: The International Group for Lean Construction, pp. 196-205.

Anklam, P. (2003)- KM and the social network., Analysis, 6(May), pp. 24-28. Available at: http://www.jedbrubaker.com/wp-content/uploads/2010/02/brubaker-vertesi-deathsns.pdf.

Bastian, M., Heymann, S. and Jacomy, M. (2009). Gephi: An Open Source Software for Exploring and Manipulating Networks. In: Third International AAAI Conference on Weblogs and Social Media, pp. 361-362. doi: 10.1136/qshc.2004.010033.

Castillo, T., Alarcón, L. F. and Salvatierra, J. L. (2016). Last Planner System, social networks and performance of construction projects. In: IGLC 2016 - 24th Annual Conference of the International Group for Lean Construction, pp. 1-10. 
Castillo, T., Alarcón, L. F., Salvatierra, J. L. and Alarcón, D. (2015). Analyzing the Interrelation Between Management Practices, Organizational Characteristics and Performance Analyzing the Interrelation Between Management Practices, Organizational Characteristics and Performance Indicators for. In: IGLC 2015 - 23rd annual conference of the International Group for Lean Construction, Perth, Australia, pp. 691-700.

Flores, J., Ruiz, J. C., Alarcón, D., Alarcón, L. F., Salvatierra, J. L. and Alarcón, I. (2014). Improving Connectivity and Information Flow in Lean Organizations - Towards an Evidence-Based Methodology. In: IGLC 2014 - 22nd Annual Conference of the International Group for Lean Construction, pp. 1109-1120.

Greenwood R, Empson, L. (2003). The professional partnership: Relic or exemplary form of governance?, Organization Studies, 24(6), pp. 909-933.

Hoppe, B. and Reinelt, C. (2010). Social network analysis and the evaluation of leadership networks, Leadership Quarterly, 21(4), pp. 600-619. doi: 10.1016/j.leaqua.2010.06.004.

Oluwatayo, A. A. and Amole, D. (2013). Ownership, structure, and performance of architectural firms, Frontiers of Architectural Research. Elsevier, 2(1), pp. 94-106. doi: 10.1016/j.foar.2012.12.001.

Oluwatayo, A. A. and Amole, D. (2014). Organizational Structure of Architectural Firms and Their Performances, International Journal of Construction Engineering and Management, 3(1), pp. 1-12. doi: 10.5923/j.ijcem.20140301.01.

Priven, V. and Sacks, R. (2013). Social network development in Last Planner System implementations. In: IGLC 2013 - 21st Annual Conference of the International Group for Lean Construction 2013, IGLC 2013, pp. 474-485. Available at: https://www.engineeringvillage.com/share/document.url?mid=cpx_772ff42f147219c4 589M39cd10178163125\&database $=$ cpx.

Zayed, T., Elwakil, E. and Ammar, M. (2012). A Framework for Performance Assessment of Organizations in the Construction Industry, International Journal of Architecture, Engineering and Construction, 1(4), pp. 199-212. doi: 10.7492/IJAEC.2012.022.

Zhou, H. and de Wit, G. (2009). Determinants and dimensions of firm growth., SCALES - Scientific AnaLysis of Entrepreneurship and SMEs, (February). Available at: http://www.entrepreneurship-sme.eu/pdf-ez/H200903.pdf. 